\title{
Rab32 and Rab38 genes in chordate pigmentation: an evolutionary perspective
}

Ugo Coppola, Giovanni Annona, Salvatore D'Aniello* and Filomena Ristoratore*

\begin{abstract}
Background: The regulation of cellular membrane trafficking in all eukaryotes is a very complex mechanism, mostly regulated by the Rab family proteins. Among all membrane-enclosed organelles, melanosomes are the cellular site for synthesis, storage and transport of melanin granules, making them an excellent model for studies on organelle biogenesis and motility. Specific Rab proteins, as Rab32 and Rab38, have been shown to play a key role in melanosome biogenesis. We analysed the Rab32 and Rab38 genes in the teleost zebrafish and in the cephalochordate amphioxus, gaining insight on their evolutionary history following gene and genome duplications.

Results: We studied the molecular evolution of Rab supergroup III in deuterostomes by phylogenetic reconstruction, intron and synteny conservation. We discovered a novel amino acid stretch, named FALK, shared by three related classes belonging to Rab supergroup III: Rab7L1, Rab32LO and Rab32/Rab38. Among these, we demonstrated that the Rab32LO class, already present in the last common eukaryotic ancestor, was lost in urochordates and vertebrates. Synteny shows that one zebrafish gene, Rab38a, which is expressed in pigmented cells, retained the linkage with tyrosinase, a protein essential for pigmentation. Moreover, the chromosomal linkage of Rab32 or Rab38 with a member of the glutamate receptor metabotropic (Grm) family has been retained in all analysed gnathostomes, suggesting a conserved microsynteny in the vertebrate ancestor. Expression patterns of Rab32 and Rab38 genes in zebrafish, and Rab32/38 in amphioxus, indicate their involvement in development of pigmented cells and notochord.
\end{abstract}

Conclusions: Phylogenetic, intron conservation and synteny analyses point towards an evolutionary scenario based on a duplication of a single invertebrate Rab32/38 gene giving rise to vertebrate Rab32 and Rab38. The expression patterns of Rab38 paralogues highlight sub-functionalization event. Finally, the discovery of a chromosomal linkage between the Rab32 or Rab38 gene with a Grm opens new perspectives on possible conserved bystander gene regulation across the vertebrate evolution.

Keywords: Pigmentation, Amphioxus, Zebrafish, Synteny, Phylogeny, Intron Conservation, Gene Duplication, Genome Duplication

\section{Background}

Intracellular compartmentalization, via membranedelimited organelles, is a fundamental feature of the eukaryotic cell and membrane trafficking between organelles became vital for these cells.

These mechanisms are typically regulated by Rab proteins, which form by far the biggest family among the small GTPases, with more than 60 members in humans [1]. These proteins play a crucial role in the regulation of cellular membrane trafficking in all eukaryotes [2].

\footnotetext{
* Correspondence: salvatore.daniello@szn.it; filomena.ristoratore@szn.it Department of Biology and Evolution of Marine Organisms, Stazione Zoologica Anton Dorhn, Villa Comunale, 80121 Napoli, Italy
}

This role is orchestrated mainly by the switching between the GTP/GDP-bound states of these proteins, controlled by the guanine nucleotide exchange factors (GEF) and GTPase activating proteins (GAP). Most Rab GTPases consist of 220 amino acids and are roughly $24 \mathrm{kDa}$ [3]. Rab proteins possess some conserved domains: the P-loop, a well-known nucleotide binding motif, fundamental for the switching between GTP/ GDP-bound states; Switch I and Switch II that are necessary for the binding of guanine nucleotides [4]. Each Rab has a distinct subcellular localization and regulates a specific transport step. Evolutionary studies suggest that twenty Rab proteins, divided into six supergroups, 
were already present in the last eukaryotic common ancestor (LECA) [5]. The number of Rabs in metazoans is extremely variable due to the occurrence of several gene gains and losses [5]. The genomes of all eukaryotes encode multiple members of the Rab family, from 10-20 in most unicellular eukaryotes [6-8] to over 60 genes in multicellular organisms $[9,10]$.

The high number of Rab expansions and secondary losses in several eukaryotic lineages suggest a complex evolutionary history of this family [11]. Among all membrane-enclosed organelles, melanosomes represent an excellent model for studying the biogenesis and motility of these structures [12]. Melanosomes, lysosome-related organelles (LRO), are the cellular site for synthesis, storage and transport of melanin granules that provide colour to tissues and are involved in photoprotection. Melanosomes are present in mammalian skin melanocytes, in choroidal melanocytes, in retinal pigment epithelial (RPE) cells of the eye, and in melanophores of teleosts and amphibians [13]. Specific Rab proteins belonging to supergroup III, Rab32 and Rab38, play a key role in melanosome biogenesis [12]. This process has been well described in mammals where melanosome formation is conventionally divided into four steps. Rab32 and Rab38, together with effector proteins like AP-3, AP-1, and BLOC-2, mediate the transport of enzymes fundamental for pigmentation, such as metazoan tyrosinase (Tyr) and tyrosinase-related protein (Tyrp1) [14], from trans-Golgi network endosomes to maturing melanosomes (step II-III) [15].

It has been shown that a point mutation in the conserved GTP/GDP-interacting domain (P-loop) of the Rab38 gene causes the Chocolate (cht) autosomal recessive mutation, which arose spontaneously in some mice strains [16]. The cht mice showed an oculocutaneous albinism phenotype and a weakly diluted coat colour. Rab38 and the closely related Rab32 work redundantly in melanocytes, as demonstrated by depletion of Rab32 in in vitro cultured cht epidermal melanocytes, which severely impairs the transport of Tyr and Tyrp1 to melanosomes, resulting in severe hypopigmentation [12]. Mouse Rab32 and Rab38 are paralogues, sharing $67 \%$ amino acid identity and are considered to have originated from the vertebrate whole genome duplication (WGD) that occurred before the Gnathostomata radiation [17-19].

Furthermore, it has been shown that the Rab38 gene is mutated in ruby rats [20], a strain characterized by hypopigmentation and platelet storage pool deficiency related to Hermansky-Pudlak syndrome (HPS) [21]. This pathology in humans causes oculocutaneous albinism, easy bleedings, abnormal lysosomal ceroid lipofuscin and pulmonary fibrosis in 40-50 years-old patients [22]. Finally, frog (Xenopus laevis) melanophores are characterized by a strong expression of Rab32, suggesting an involvement in pigment formation [23].

Much less is known regarding invertebrate Rab32/38 gene functioning: in the ascidian Ciona intestinalis, the closest living relative of vertebrates [24], the unique Rab32/38 gene is expressed in four cells belonging to the pigment cell lineage [25]. Among these cells the otolith and ocellus, the sole pigmented sensory organs of ascidian larvae, will form [26]. Functional studies demonstrated that Rab32/38 is essential for proper pigmentation of otolith and ocellus pigmented cells [25].

In the fruit fly Drosophila melanogaster Rab-RP1 (Rab32) is expressed in eye lysosomes and lipid droplets of adipose tissue [27], and its mutation causes eye hypopigmentation (lightoid) [28].

To gain insight into deuterostome evolution and the possible function of the Rab32 and Rab38 genes, we investigated the molecular evolution and spatio-temporal localization during development in two key animal models: the cephalochordate Branchiostoma lanceolatum and the teleost Danio rerio.

Cephalochordates represent an early-branching chordate group, their genomic, anatomical and morphological features, however, make them the best available stand-in for the chordate ancestor. Amphioxus has an unduplicated genome, but possesses representatives of all vertebrate gene families [29]. Amphioxus photoreceptive system is formed by 4 different structures: Joseph cells, the lamellar body, dorsal ocelli (Hesse cells) and the frontal eye [30]. Hesse cells are traditionally considered homologue of vertebrate eye photoreceptors, whereas the frontal eye pigment cells are thought to be homologue of vertebrate RPE cells, as demonstrated by Mitf, Otx and Pax2/5/8 tissue-specific expression [31]. Tyr, Tyrp $1 / 2 a$ and Tyrp $1 / 2 b$ are coexpressed at the neurula stage in the neural tube where the first primary pigment spot will form [32].

Among vertebrates, the teleosts (32000 species) show an incredible variety of pigmentation patterns, decisive for their complex behaviour. Intriguingly, the skin pigmentation pattern of teleosts is not only due to the black/brown melanocytes, yellow/red xanthophores and reflecting iridophores, common to all vertebrates, but also to whitish leucophores and blue cyanophores that are lineage-specific novelties [33]. Teleosts are able to adapt perfectly to highly different environments, through the $\alpha$-melanophore-stimulating hormone $(\alpha-\mathrm{MSH})$ secreted by the pituitary, which is influenced by neurotransmitters such as norepinephrine [34].

Teleost genomes have undergone a third round of whole genome duplication that probably provided the raw genetic material for the teleost radiation [35-37]. This event occurred only in the teleostean lineage, amongst actynopterigians [38], and it was therefore named "teleost-specific genome duplication" (TSGD) 
[39]. It has been suggested that a strong relationship exists between these genome duplications and the extraordinary pigmentation variety in teleosts: in fact teleost genomes show a dramatically wide repertoire of genes involved in pigmentation, produced both by TSGD and small-scale gene duplications [33]. Many pigmentation genes in teleosts gained other roles, distributing ancestral functions to duplicated genes (sub-functionalization) or acquiring new one after the split (neo-functionalization) [40].

In this paper, we studied all the Rab32 and Rab38 genes present in the genomes of the amphioxus $B$. lanceolatum and the zebrafish $D$. rerio to shed light on the evolution of this subfamily of deuterostomes and gain insight into their role during chordate development.

\section{Results}

\section{Evolutionary history of Rab32 and Rab38 in Deuterostomes}

To study the evolutionary history of the Rab32 and Rab38 we performed a phylogenetic reconstruction starting from a database of manually curated supergroup Rab III sequences (see Additional files 1 and 2). We included sequences from vertebrates (Petromyzon marinus, Callorinchus milii, Lepisosteus oculatus, Latimeria chalumnae, D. rerio, Xenopus tropicalis, Anolis carolinensis, Gallus gallus, Mus musculus, and Homo sapiens), urochordates (Ciona intestinalis), cephalochordates (B. lanceolatum), hemichordates (Saccoglossus kowalevskii) and echinoderms (Strongylocentrotus purpuratus). Since Rabs are very similar to other small GTPase proteins, we only included sequences giving the higher Blast scores with known Rabs.

To obtain the best phylogenetic resolution we included representative members of Rab supergroup III: Rab32, Rab38, Rab7, Rab7L1, Rab9, Rab23 (see Additional file 2). Regarding Rab32 and Rab38, our analysis allowed to identify two genes in amphioxus and five in zebrafish genomes. Phylogenetic analysis revealed four strongly supported clades: Rab7, Rab9, Rab23 and a clade formed by Rab7L1, Rab32LO, Rab32 and Rab38. Among these, Rab7, Rab9 and Rab23 represent phylogenetically robust monophyletic groups (Fig. 1), while the Rab7L1 (blue box) results as sister group of Rab32LO (yellow box) and Rab32/Rab38 (red box).

Rab32LOs, previously named Rab32B [11], were described as already present in choanoflagellates (Capsaspora owczarzaki), sponges (Amphimedon queenslandica) and cnidarians (Nematostella vectensis), and therefore considered as LECA gene. Moreover, we found Rab32LO in protostomes (mollusks and platyhelminthes) and in deuterostomes (such as sea urchins and amphioxus). Strikingly, our study highlighted its loss in Olfactores (urochordates plus vertebrates) [24] prompting us to name it Rab32LO (Lost in Olfactores).
Unfortunately, our phylogenetic survey did not clarify the relationships among the vertebrate Rab32 and Rab38, and invertebrate Rab32/38 genes (Fig. 1 red box) due to the high degree of sequence similarity. The phylogenetic tree (Fig. 1) shows that amphioxus possesses a Rab32LO and a unique Rab32/38 member. Zebrafish presents three Rab38 (Rab38a, Rab38b and Rab38c), and two Rab32 genes (Rab32a and Rab32b). Strikingly, the position of Rab32b in the tree is inconsistent with species phylogeny, probably due to its fast evolutionary rate (Fig. 1). A vertebrate-specific phylogenetic analysis was performed to elucidate the relationship existing between Rab32 and Rab38 proteins in this group (see Additional files 3 and 4).

With the aim to distinguish between Rab32 and Rab38 proteins, we compared the three conserved Rab domains across several deuterostome species, using the human RAB6A as reference [4]: the P-loop (green) located at amino acids 20-27, the Switch I (turquoise) at amino acid positions 38-49 and the Switch II (magenta) at amino acids 69-81 (Fig. 2). To better understand the conservation of protein domains, we also added all human proteins of Rab supergroup III and one representative of other five Rab supergroups. The alignment shows a high degree of conservation for three known domains in deuterostomes. The general core sequence of the P-loop is GxxxxGKT(S) in all subfamilies. We found that the $2^{\text {nd }}$ residue is diagnostic for Rab classification in vertebrates (GExxxGKT for Rab32s or GDxxxGKT for Rab38s). Switch I (consensus FSxxYxxTIGVD) and Switch II (consensus DIAGxERFGxMTR) are highly conserved across deuterostomes, showing sequence divergence only in zebrafish Rab32b. Moreover, we identified for the first time the existence of an ultra-conserved stretch of four amino acids (FALK) located at the end of Switch I that is present only in Rab32, Rab38, Rab32LO and Rab7L1 subfamily members (black arrow in Fig. 1, yellow in Fig. 2) among Rab supergroup III. The presence of two conserved Histidine residues exclusively in Rab32LO Switch II (Fig. 2) confirms the fact that Rab32LO is a distinct class within supergroup III, supporting our phylogenetic data. In order to clarify the poorly resolved relationship among invertebrate Rab32/38 and vertebrate Rab32 and Rab38 we searched for an evolutionary signature of conserved introns, analysing the gene structure of human Rab32 and Rab38 in comparison with Branchiostoma, Ciona and Lottia Rab32/38 genes. Strikingly, we found two introns that show conserved position and phase, suggesting a common ancestral origin (see Additional file 5).

\section{Rab32 and Rab38 synteny conservation}

To further improve knowledge on the evolutionary history of the Rab32 and Rab38 subfamilies, we analysed their chromosomal neighbourhood genes in available 


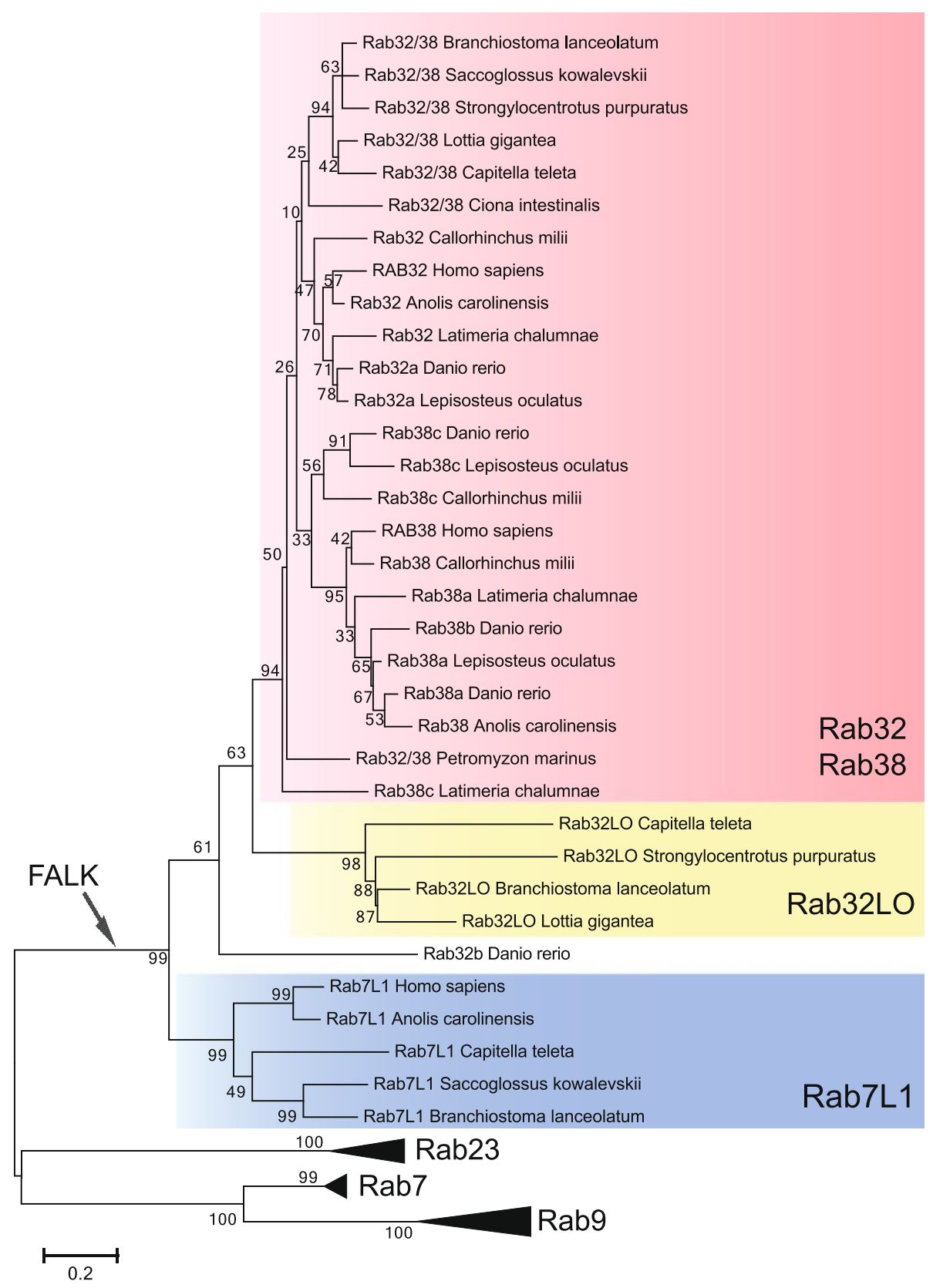

Fig. 1 Evolution of the Rab32 and Rab38 subfamily in deuterostomes. Numbers at the branches indicate replicates obtained using the Maximum Likelihood estimation method. 247 sites were used for tree inference. Colored boxes highlight three classes of proteins: Rab7L1 present in invertebrates and vertebrates (blue box), Rab32LO present in protostomes, echinoderms and cephalochordates (yellow box), the Rab32 and Rab38 cluster present in all the deuterostomes (red box). Black arrow indicates the acquisition of FALK amino acid stretch at the stem of Rab7L1, Rab32LO, Rab32 and Rab38 evolution. Triangles indicate monophyletic clades belonging to Rab supergroup III (Rab7, Rab9, Rab23)

deuterostome genomes (Fig. 3). We searched in genomes of invertebrates (S. kowalevskii, S. purpuratus, B. floridae, C. intestinalis) and, among vertebrates, we selected the lamprey $P$. marinus for the agnathans, the elephant shark C. milii [41] and spotted gar $L$. oculatus as representatives of non-teleost fish [42], D. rerio for teleosts, the lizard A. carolinensis in the Sauropsida clade, and $H$. sapiens and $M$. musculus among mammals. We did not find chromosomal conservation in lamprey. On the other hand, we discovered a high degree of synteny conservation within both gnathostome Rab32s loci (Fig. 3a) and Rab38s loci (Fig. 3b). Nevertheless, the genes flanking Rab32 are different from those surrounding Rab38. To demonstrate the orthology of syntenic genes we performed ad hoc phylogenies of Tab, Nox, Fzd and Stxbp genes (see Additional file 6). 


\begin{tabular}{|c|c|c|c|c|c|}
\hline \multicolumn{2}{|l|}{ Species } & Gene & P-Loop & Switch I & Switch II \\
\hline \multirow{2}{*}{\multicolumn{2}{|c|}{ Capitella teleta }} & $\operatorname{Rab} 32 / 38$ & GELGTGKT & FSQHYRATIGVDFALK & \\
\hline & & Rab32LO & GEFGVGKT & FVPSYKMTIGVDFSMK & $A G H$ \\
\hline \multicolumn{2}{|l|}{ Lottia gigantea } & $\operatorname{Rab} 32 / 38$ & GELGTGKT & FSQHYRATIGVDFALK & \\
\hline & & Rab32LO & GEFGVGKT & FFPNYKLTIGVDFALK & $\mathrm{GH}$ \\
\hline \multicolumn{2}{|c|}{ Paracentrotus lividus } & $\operatorname{Rab} 32 / 38$ & GDLGVGKT & FSQHYRATIGVDFALK & \\
\hline & & Rab32LO & GEFGVGKT & FSPNYKLTIGVDFALK & $\mathrm{AGHE}$ \\
\hline \multirow{2}{*}{\multicolumn{2}{|c|}{$\begin{array}{l}\text { Saccoglossus kowalevskii } \\
\text { Branchiostoma lanceolatum }\end{array}$}} & $\operatorname{Rab} 32 / 38$ & GDLGTGKT & FSQHYRATIGVDFALK & [AGQE] \\
\hline & & $\operatorname{Rab} 32 / 38$ & GDLGTGKT & FSQHYRATIGVDFALK & סOת \\
\hline & Rab32LO & GEFGVGKT & FSPNYKLTIGVDFALK & $\mathrm{AGH}$ \\
\hline & & $\operatorname{Rab} 32 / 38$ & GELGVGKT & FSQHYRATIGVDFALK & AGQER \\
\hline \multicolumn{2}{|c|}{ Ciona intestinalis } & $\operatorname{Rab} 32 / 38$ & GELGVGKT & FSHGYRATIGVDFALK & [AGQERFGNMTR \\
\hline \multicolumn{2}{|c|}{ Callorhinchus milii } & Rab32 & GELGVGKT & FSQNYRATIGVDFALK & IAGQERFGNMTR \\
\hline & & Rab38a & GDLGVGKT & FSQHYRATIGVDFALK & IAGQERFGNMTR \\
\hline \multirow{2}{*}{\multicolumn{2}{|c|}{ Lepisosteus oculatus }} & $\operatorname{Rab} 38 \mathrm{C}$ & GDLGVGKT & FSQHYRATIGVDFALK & )IAGQERFGNMTR \\
\hline & & Rab32 & GELGVGKT & FSQHYRATIGVDFALK & IAGQER \\
\hline & & $\operatorname{Rab} 38 a$ & GDLGVGKT & YSPNYRATIGVDFALK & IAGQER \\
\hline & & $\operatorname{Rab} 38 \mathrm{c}$ & GDLGVGKT & FSQHYRATIGVDFALK & JAAGQERY \\
\hline & Rab32a & GELGVGKT & FSQHYRATIGVDFALK & IAGQER \\
\hline \multicolumn{2}{|l|}{ Danio rerio } & Rab32b & GDHKVGKS & FYEELKTS IGVDFSMK & DIAGQERVRGLNR \\
\hline & & $\operatorname{Rab} 38 a$ & GDLGVGKT & FSPNYRATIGVDFALK & IAGQERFGNM \\
\hline \multirow{3}{*}{\multicolumn{2}{|c|}{ Latimeria chalumnae }} & Rab38b & GDLGVGKT & YSTNYRATIGVDFALK & DIAGQEF \\
\hline & & $\operatorname{Rab} 38 \mathrm{C}$ & GDLGVGKT & FSQHYRATIGVDFALK & IAGQERYGNM! \\
\hline \multirow{2}{*}{\multicolumn{2}{|c|}{ Latimeria chalumnae }} & Rab32 & GELGVGKT & FSQHYRATIGVDFALK & IAGQERFGNM \\
\hline & & $\operatorname{Rab} 38 a$ & GDLGVGKT & FSPHYRATIGVDFALK & IAGQERFGNMTR \\
\hline \multirow{2}{*}{\multicolumn{2}{|c|}{ Xenopus tropicalis }} & $\operatorname{Rab} 38 \mathrm{c}$ & GEIGVGKT & FYHHYRATIGVDFALK & IAGQERFGNMI \\
\hline & & Rab32 & GELGVGKT & FSQHYRATIGVDFALK & IAGQERFGNMTR \\
\hline & $\operatorname{Rab} 38$ & GDLGVGKT & FSPHYRATIGVDFALK & IAGQERFGNMT \\
\hline \multicolumn{2}{|l|}{ Gallus gallus } & Rab32 & GELGVGKT & FSQHYRATIGVDFALK & IAGQERFGNMTR \\
\hline \multirow{2}{*}{\multicolumn{2}{|c|}{ Anolis carolinensis }} & $\operatorname{Rab} 38$ & GDLGVGKT & FSPHYRATIGVDFALK & JIAGQERFGNMTR \\
\hline & & Rab32 & GELGVGKT & FSQHYRATIGVDFALK & IAGQERFGNMT \\
\hline & $\operatorname{Rab} 38$ & GDLGVGKT & FSPHYRATIGVDFALK & IAGQEREGNM \\
\hline \multirow{2}{*}{\multicolumn{2}{|c|}{ Mus musculus }} & Rab32 & GELGVGKT & FSQHYRATIGVDFALK & IAGQEREGNMTR \\
\hline & & Rab38 & GDLGVGKT & FSSHYRATIGVDFALK & IAGQERFGNM \\
\hline \multirow{2}{*}{\multicolumn{2}{|c|}{ Homo sapiens }} & RAB32 & GELGVGKT & FSQHYRATIGVDFALK & IAAGQERFGNM] \\
\hline & & RAB38 & GDLGVGKT & FSSHYRATIGVDFALK & DIAGQERFGNM \\
\hline \multicolumn{2}{|c|}{ Capitella capitella } & Rab7L1 & GDPGVGKT & YTKDYKATLGVDFALK & \\
\hline \multicolumn{2}{|c|}{ Saccoglossus kowalevskii } & Rab7L1 & GDATVGKT & FRREYKTTIG------ & ther \\
\hline Branchiostoma & iceolatum & Rab7L1 & GDATVGKT & FKREYKATVGVDFALK & DV \\
\hline Homo sapiens & & RAB7L1 & GDAAVGKT & FSKHYKSTVGVDFALK & $\mathrm{AGQEF}$ \\
\hline Homo sapiens & (group III) & RAB7A & GDSGVGKT & FSNQYKATIGADFLIK & DTAGQ \\
\hline & (group III) & RAB9A & GDGGVGKS & FDTQLFHTIGVEFLNK & DTAGQEI \\
\hline & (group III) & RAB9B & GDGGVGKS & FDTQLFHTIGVEFLNK & ERSLRT \\
\hline & (group III) & RAB23 & GNGAVGKS & FTKDYKKTIGVDELER & TAGQEEFDAITK \\
\hline & (group I) & RAB18 & GESGVGKS & FDPELAATIGVDFKVK & DTAGQERERTLTP \\
\hline & (group II) & RAB5A & GESAVGKS & FVKGQFHEFQESFLTQ & YHSLAP \\
\hline & (group IV) & RAB2 & GDTGVGKS & FQPVHDLTIGVEFGAR & DTAGQESFRSITR \\
\hline & (group V) & $\mathrm{RAB} 6 \mathrm{~A}$ & GEQSVGKT & FDNTYQATIGIDELSK & RERSLIP \\
\hline & (group VI) & RAB28 & GDGTSGKT & FGKQYKQTIGLDFFLR & DIGGQTIGGKMLD \\
\hline
\end{tabular}

Fig. 2 Alignment of Rab supergroup III domains. The alignment shows the amino acid conservation of three Rab domains: the P-loop, involved in trafficking (green), the Switch I (turquoise) and the Switch II (magenta) important for supporting the binding with other molecules. Downstream of Switch I, four ultra-conserved amino acids are highlighted, named FALK (yellow). The white background indicates changes in amino acid composition during evolution. At the bottom, human representatives of other Rab supergroups are reported to show the absence of FALK

The existence of a chromosomal region conserved between $H$. sapiens and some teleosts, containing Rab38, Grm5 and Tyr genes has been already described in a comparative study [33]. Our syntenic survey across the vertebrates extended the conservation to the holocephalan elephant shark, the nonteleost actinopterygian spotted gar, the anole lizard and mice. Moreover, we also showed that Rab32 genes are always linked to a Grm family member (Grm1) (Fig. 3). Collectively, our data suggest an ancestral chromosomal linkage between a Rab32/38 and Grm1/
5 gene, already present in the vertebrate's common ancestor (Fig. 3). We carried out the phylogeny of the Grm family to demonstrate the orthology among vertebrate Grm1 genes and Grm5 genes, respectively (see Additional file 7), further supporting our hypothesis of an ancient chromosomal linkage. In more detail, we found one Rab32 always coupled with the melanoma oncogene Grm1 [43, 44], while one Rab38 is always close to Grm5, a gene playing a fundamental role in many human disorders such as schizophrenia [45] and autism [46]. 


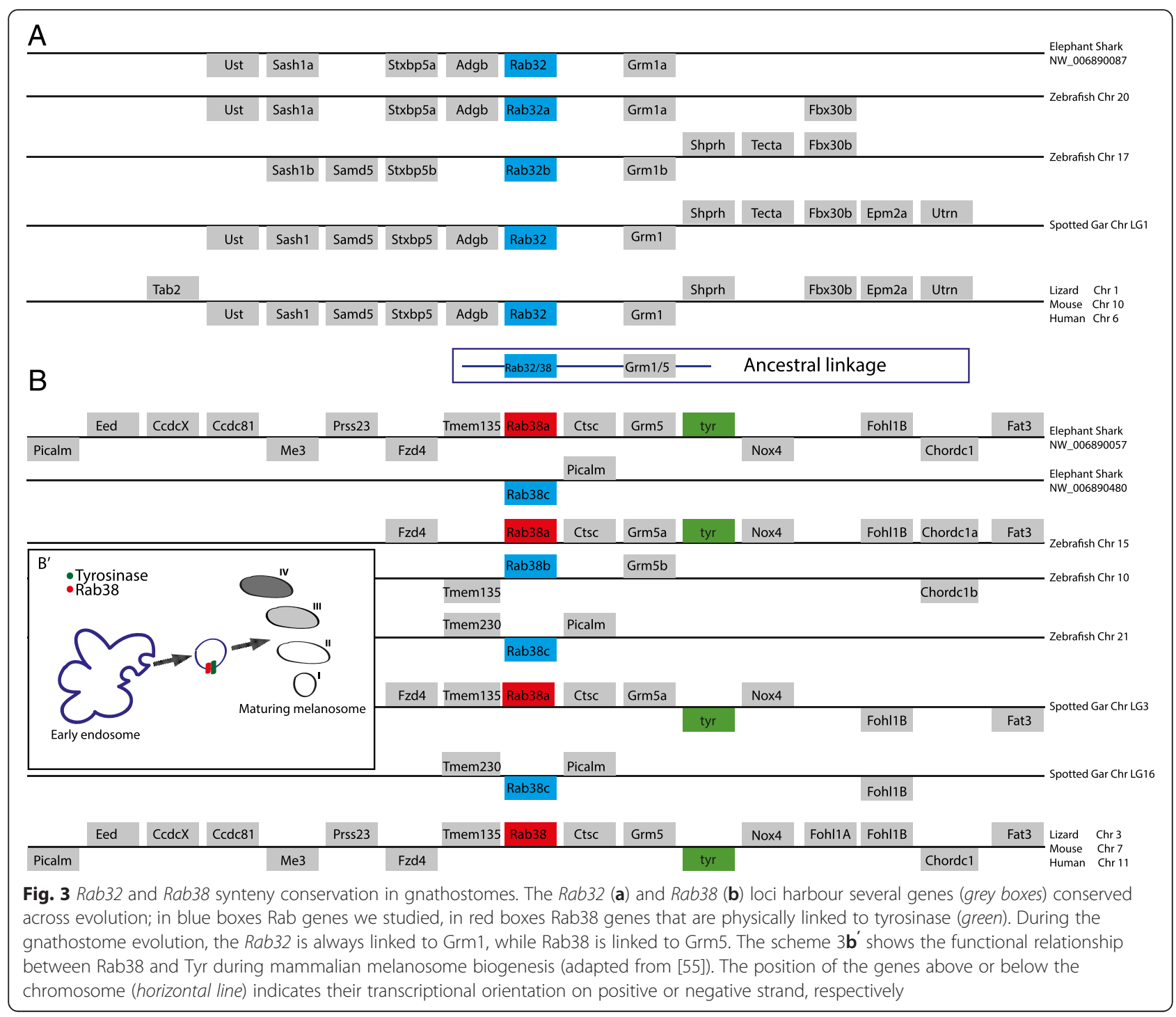

Among zebrafish Rab38 paralogues we found a higher degree of syntenic conservation in the Rab38a locus (number of genes and organization) than in the Rab38b and Rab38c loci (Fig. 3b). For instance, we found that only the zebrafish Rab38a maintained the linkage with the Tyr gene, as is the case in the unique tetrapod Rab38 paralogue. Similarly, in elephant shark and spotted gar this linkage is retained in only one of the two Rab38 paralogons (Fig. 3b).

Additionally, in tetrapod FohllA and Fohl1B, and the Coiled-coil domain containing proteins $(C c d c)$, belonging to a big family whose role is completely unknown, are duplicated on the same chromosomal stretch (Fig. 3b). The mammalian Rab38 loci show an interesting peculiarity, they present several insertions of receptors belonging to the same family derived from tandem gene duplication events (see Additional file $8 \mathrm{~A}$ ). On mouse chromosome 7 , beside the two
Fohl1s, there are fifteen Vomeronasal 2 Receptors $(V m n 2 r)$, known for their crucial role in mouse ultrasensitive chemodetection [47] and fourteen Olfactory Receptors (OR) [48], belonging to a very large family in mice, explaining their extraordinary odour sensitivity and ability to discriminate scents [47, 48]. Interestingly, in the orthologous position, the human chromosome 11 harbours seven tripartite motif proteins (TRIM), which are involved in a plethora of biological processes, in particular the immune response [49] (see Additional file 8A).

On the other hand, we did not find any synteny conservation in Rab loci of invertebrate deuterostomes. The unique trace of microsynteny was found in the sea urchin and amphioxus gene scaffolds, between Rab32LO and $\operatorname{Tim} 9$, an evolutionarily conserved transporter involved in metabolite import by mammalian mitochondria [50] (see Additional file 8B). 


\section{Rab32 and Rab38 gene expression patterns in amphioxus and zebrafish}

To investigate the possible role of Rab genes in the amphioxus B. lanceolatum, we cloned the Rab32LO and Rab32/38 genes and studied their expression pattern by whole mount in situ hybridization (WISH) in embryos at different developmental stages (Fig. 4). Unfortunately, Rab32LO was not detectable by in situ hybridization at any analysed stage, confirmed by the low levels of expression detected by real-time RT-PCR experiments (see Additional file 9). Rab32/38 was first observed at the gastrula stage in presumptive notochord territories (Fig. 4a), and later during development, at the neurula stage, it appears clearly in the notochord, from the most rostral part along the length of the embryo without reaching the caudal part (Fig. 4b, c). The Rab32/38 expression in the notochord has been confirmed by the transverse section (Fig. 4d). At the pre-mouth larval stage of development, the Rab32/38 expression in the notochord turns off and a novel territory of expression is visible in the pharynx region (Fig. 4e).

The same approach was used to investigate the expression pattern of Rab32 and Rab38 during zebrafish embryogenesis. It was impossible to amplify $R a b 32 b$ from embryonic and adult tissues (brain and eye), suggesting that this gene is either expressed at very low levels or only under specific environmental conditions. Rab32a expression has been detected in the presumptive posterior axial mesoderm starting from $6 \mathrm{~h}$ postfertlization (hpf) (shield stage), as it was already described by Thisse and collaborators [51] (Fig. 5a). During embryo elongation (tail bud stage), the Rab32a positive cells were localized near the animal pole and form a longitudinal band in the dorsal midline, the developing notochord that includes the tail bud region (Fig. 5b). Moreover, at this stage, a signal is detectable in the Kupffer's vesicle (Fig. 5b), a small but distinctive epithelial sac, situated posteriorly near the yolk [52]. During segmentation (24 hpf), the expression of Rab32a becomes weaker in the notochord (Fig. 5c), while it starts to be expressed in the eyes, as well as in cells that appear to be migrating melanoblasts according to their position (Fig. 5c-f). Starting from the long-pec stage (48 hpf), the expression in migrating melanoblasts disappears and is retained only in the retinal pigmented epithelium of the eye and in the notochord (Fig. $5 \mathrm{~g}, \mathrm{~h}$ ). At this stage, a
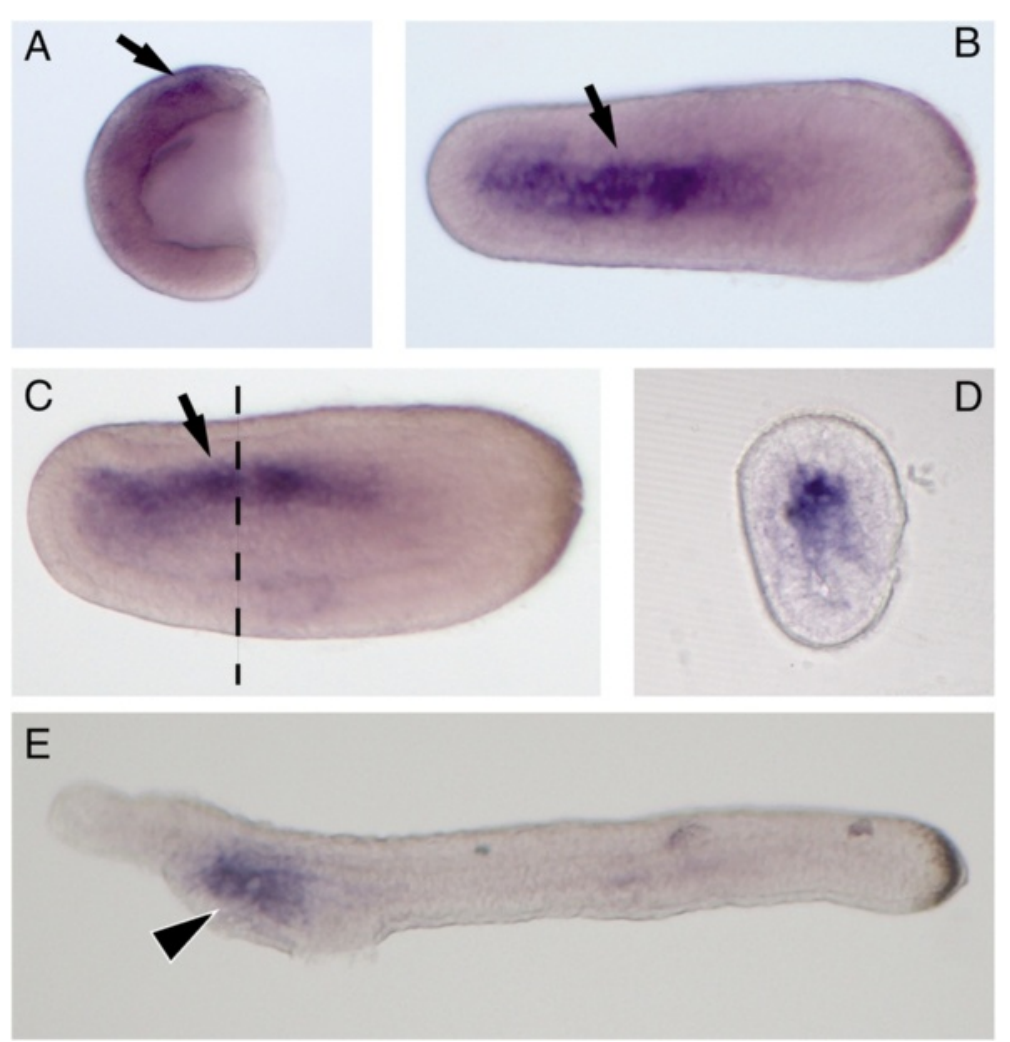

Fig. 4 Rab32/38 expression pattern during amphioxus embryogenesis. Rab32/38 has been observed in notochord presumptive territories at the gastrula stage (a, black arrow), while later in development at the neurula stage it is expressed in notochord, mainly in the rostral part (b-c, black arrow). $\mathbf{d}$ is a vibratome section $(15 \mu \mathrm{m})$ of the neurula specimen showed in $\mathbf{b}-\mathbf{c}$, at the level of the vertical dashed line. At the pre-mouth larval stage, Rab32/38 expression in the notochord turns off while a positive signal appears in the pharynx region (e, arrowhead) 

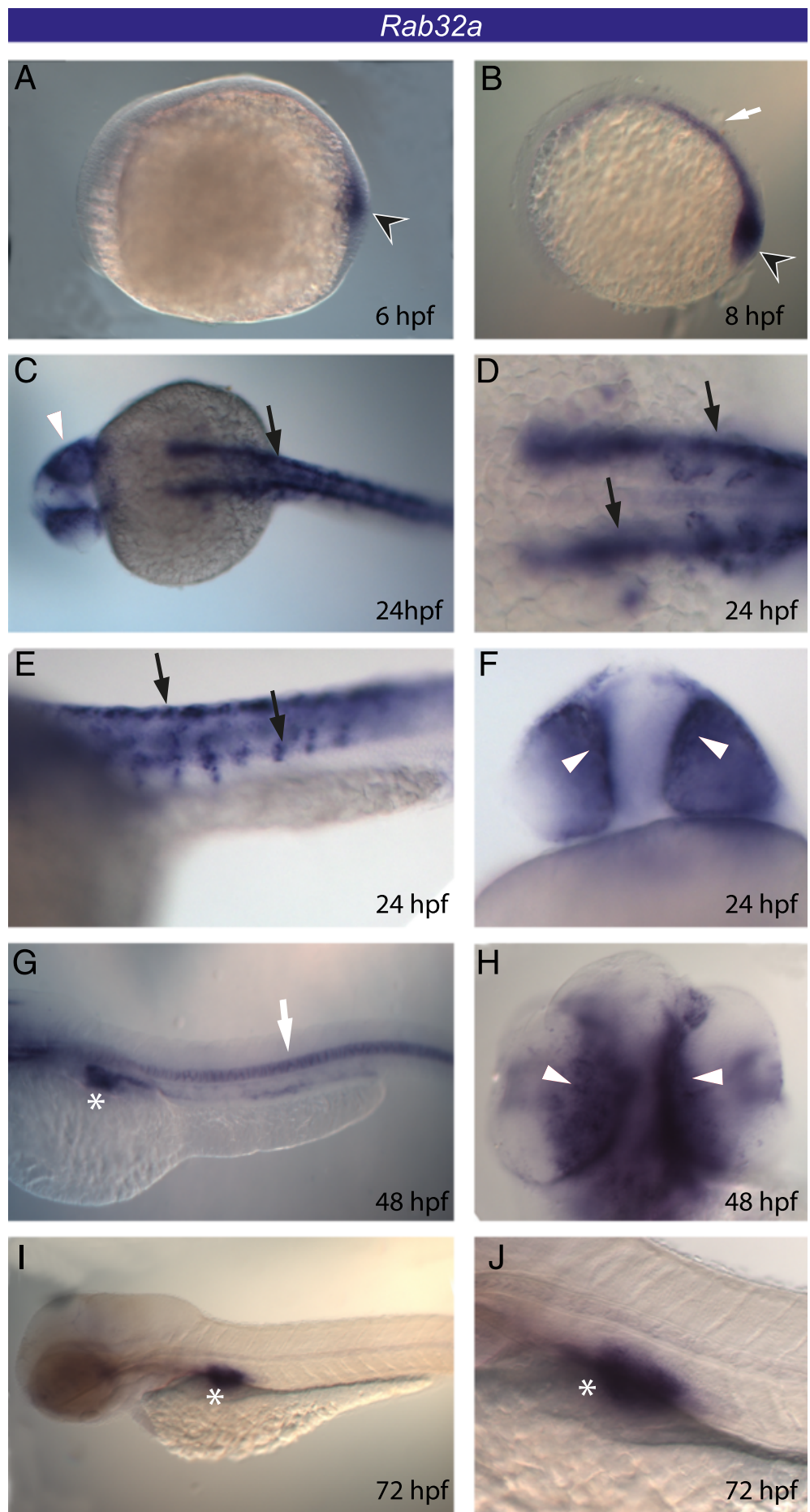

Fig. 5 Rab32a expression pattern during zebrafish embryogenesis. Rab32a has been observed in the presumptive posterior axial mesoderm (arrowhead) at $6 \mathrm{hpf}$ (a) and in the developing notochord (white arrow) and Kupffer's vesicle (arrowhead) at 8 hpf (b). At 24 hpf, it is present in RPE (white arrowhead), notochord and migrating neural crest cells (black arrows) (c-f). At 48 hpf the signal disappears in neural crest cells, but persists in RPE and notochord (white arrows) (g-h) and appears in the swim bladder (g, white asterisk). The expression in the swim bladder persists at $72 \mathrm{hpf}$ larvae (i-j, white asterisk) 
strong signal becomes visible (Fig. $5 \mathrm{~g}$ ) in the swim bladder, the organ that adult teleosts use for buoyancy and breathing, and persists up to the protruding-mouth larval stage (72 hpf; Fig. 5i, j).

Regarding Rab38 paralogues, Rab38a is expressed across the pharyngula embryonic period (24-48 hpf) (Fig. 6a-d). Embryos at $24 \mathrm{hpf}$ show a faint signal in RPE and a strong one in migrating neural crest cells, presumably migrating melanoblasts (Fig. 6a, b). At this stage, a low level of expression is detectable in the mid-ventral region of brain as well (Fig. 6a). Later in development (48 hpf) expression is only observed in the RPE (Fig. 6c, d). Rab38b is expressed only at late developmental stages (Fig. 6e-h); at $48 \mathrm{hpf}$ it is expressed in a small region of the pharyngeal arch and in the developing swim bladder (Fig. 6e, f), while at 72 hpf only the signal in the swim bladder persists (Fig. 6g, h). The gene Rab38c is expressed from 6 to $72 \mathrm{hpf}$ with a strong signal in the head (as shown in Fig. 6i, j for 24 hpf).

\section{Discussion}

\section{Rab32 and Rab38 toolkit in animal evolution}

Our phylogeny evidences three distinct branches: Rab7L1, Rab32LO and Rab32/Rab38, which share the highly conserved FALK stretch downstream of the Switch I domain and emerged after splitting from Rab23, Rab7 and Rab9 groups (Fig. 1). Although the FALK function is still unknown, its high degree of sequence conservation in all analysed proteins suggests that it could be responsible for important functional properties (Fig. 2).

It has been suggested that the Rab32/38, already described as Rab32A and Rab32LO, previously named Rab32B, present in the Last Eukaryotic Common Ancestor were already implicated in late endosomal or lysosomal trafficking [11]. Rab32LO is present in unicellular eukaryotes to chordates [11], and here we showed its loss in the lineage of Olfactores. This event could be related to the loss of ancestral functions during chordate evolution, although the biological functions of these proteins should be further investigated in the future.

Detailed analysis of the conserved Rab functional domains allowed to identify few diagnostic residues of vertebrate Rab32 and Rab38 (Fig. 2). Similarly, two Histidines are distinctive residues of the Rab32LO Switch II region. Our analyses suggest that the phylogenetic signal is weak for the heterogeneous evolutionary rate of this group of proteins, leaving the issue of vertebrate Rab32 and Rab38 origin unresolved. A possible hypothesis is that vertebrate Rab32 and Rab38 arose from a prevertebrate Rab32/38 through a vertebrate genome duplication. The study of intron conservation, considered a diagnostic tool for tracing back the evolutionary history of genes [53], showed the existence of a conserved intron code supporting a common origin for all the subfamily members (see
Additional file 5). Furthermore, the parallel evolutionary history of Rab32/38 and Grm1/5 genes is consistent with our hypothesis of a duplication event in vertebrates. In fact, in invertebrates, similarly to the Rab32/38, a single pre-duplicative Grm1/5 exists as demonstrated by the dedicated phylogeny (see Additional file 7). Interestingly, the chromosomal proximity of Rab32 to Grm1 and Rab38 to Grm5 indicates a duplication of an ancestral chromosomal region comprising Rab32/38 and Grm1/5 (Fig. 3). The retained microsynteny that we found from elephant shark to humans hints at a functional correlation between these two gene duplets. It would be challenging to find out whether the integrity of these linkages is necessary for their functioning. Collectively our phylogeny, intron and synteny conservation analyses suggest that Rab32 and Rab38 derived from a vertebrate genome duplication, therefore they are both ohnologs of the pre-vertebrate Rab32/38 gene.

We found a very high degree of chromosomal conservation among vertebrates (Fig. 3). In particular the high similarity between C. milii Rab38a and tetrapod Rab38 loci confirms that cartilaginous fishes mimic the tetrapod genomic organization better than teleosts [54]. Surprisingly, a sharp lack of synteny involving only one side of the Rab38a of spotted gar (LG16) and zebrafish (chromosome 15) loci suggests a rearrangement event in the Actinopterygii (Fig. 3b).

Vertebrates have been affected by several rounds of genome duplication that have increased the repertoire of pigmentation genes mainly in teleosts [40]. The present survey highlights the expansion of the Rab32 and Rab38 driven by a mixture of gene and genome duplications that allowed the emergence of novel functions [34]. In zebrafish the Rab32 and Rab38 reached a total of five members through the TSGD, plus single gene duplication in the Rab38 lineage.

The role of TSGD in the evolution of teleost pigmentation diversity is well-known resulting in $30 \%$ more pigmentation genes than in tetrapods. In fact, other genes involved in pigmentation are also duplicated such as Mitf, Kitl, Tyr and Tyrp [33, 40] explaining the extremely diversified body colour patterning of teleosts [40].

Intriguingly, we noticed in gnathostomes the existence of a specific linkage among two well-known players of the pigmentation process; the Tyr and Rab38, retained in all analysed tetrapods and in the elephant shark, spotted gar and zebrafish Rab38a paralogons (Fig. 3b). It has been demonstrated that the delivery of Tyr, Tyrp1 and Tyrp2 to the maturing melanosomes is required to initiate pigmentation. Rab32 and Rab38 have been shown to mediate the transport of Tyr and Tyrp1 by interacting with the ubiquitous trafficking machinery [55] (Fig. 3b'). Taking into consideration that Rab38a is the sole Rab38 

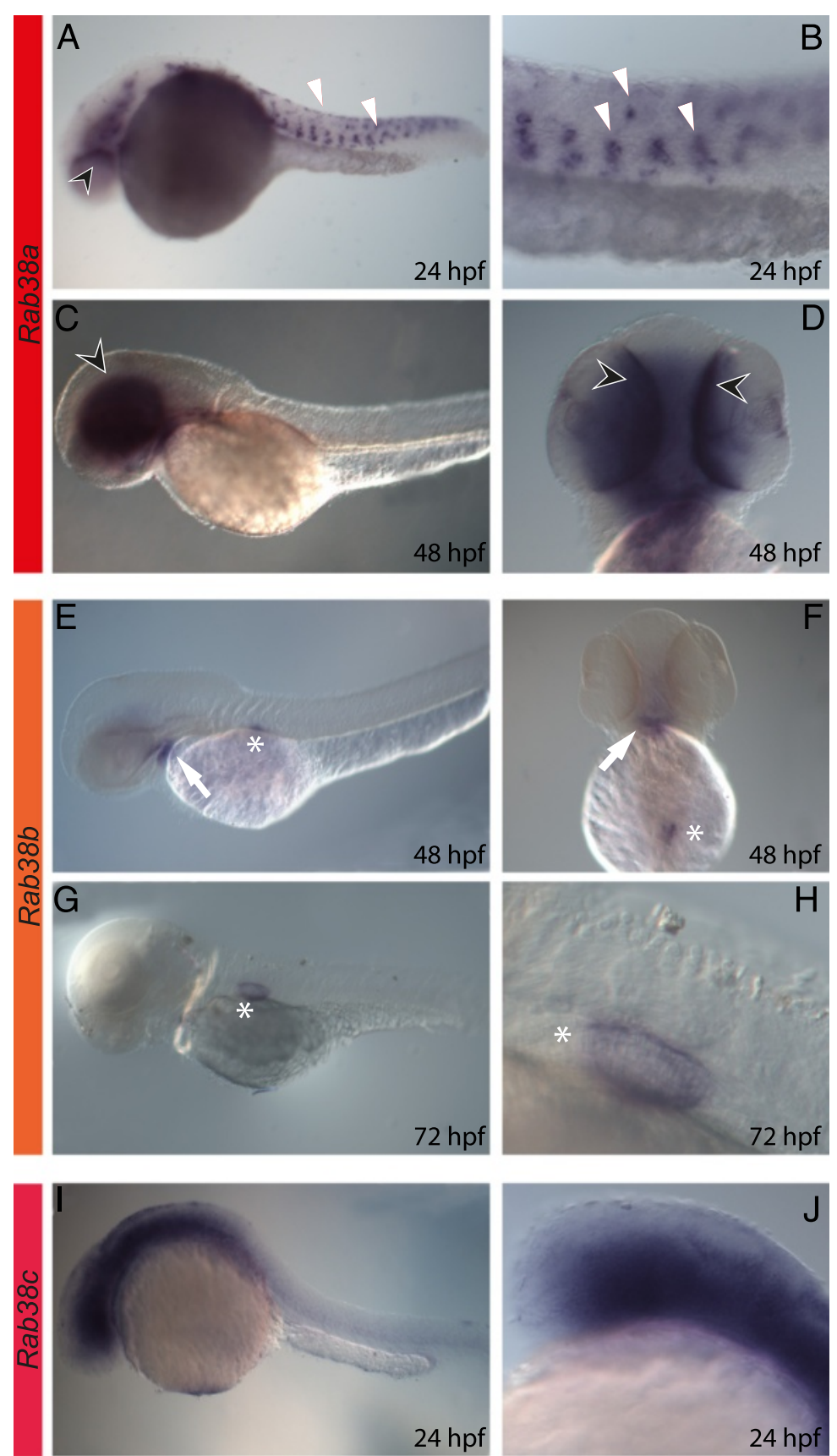

Fig. 6 Rab38s expression pattern during zebrafish embryogenesis. Rab38a is expressed across the pharyngula embryonic period (24-48 hpf) (a-d): at $24 \mathrm{hpf}$ there is a faint signal in RPE (arrowhead) and a strong one in migrating melanoblasts (a, $\mathbf{b}$, white arrowhead) and a low level of expression is detectable in the mid-ventral region of brain (a); at $48 \mathrm{hpf}$ the expression is visible only in the RPE (black arrowhead) (c, d). Rab38b is expressed only at late developmental stages (e-h): at 48 hpf in a small region of the pharyngeal arches (white arrow) and in the developing swim bladder (e, f, white asterisks), while at $72 \mathrm{hpf}$ only in swim bladder ( $\mathbf{g}, \mathbf{h}$, white asterisks). The gene Rab38c gene is strongly expressed in the head region (i and $\mathbf{j}$ for $24 \mathrm{hpf}$ larvae). Lateral view in all images (anterior is on the left) except $\mathbf{d}$ and $\mathbf{f}$ that are ventral (anterior on the top)

member to be expressed in zebrafish pigment-producing cells and its chromosomal vicinity to Tyr, we hypothesize a bystander gene regulation modality during vertebrate melanosomes biogenesis by means of a locus control region, as previously demonstrated for developmental genes [56].

\section{Expression profile in zebrafish and amphioxus}

In mammals, melanocytes, platelets and mast cells, rich in LROs, exhibit a high level of Rab32 [57], whereas Rab38 is restricted to melanocytes and lung epithelial cells $[58,59]$. In zebrafish, we have identified two Rab32 
and three Rab38 genes (Fig. 1). Rab32a is expressed in the embryonic pigmentary lineage, including both melanocytes and RPE, as described in other vertebrates. Moreover, it is expressed during notochord development, a feature that seems to be specific of zebrafish ([51] and present study). Recently it has been proposed that Rab32a function is required for correct formation of the notochord vacuoles in zebrafish [60]. Finally, Rab32a is expressed in the natatory vesicle of zebrafish (Fig. 5), also known as the swim bladder, an organ whose relationship with the tetrapod lung is still debated [61]. Considering that invertebrate Rab32/38 has an important role in melanogenesis, as demonstrated by a functional study in C. intestinalis [25], and that this role is maintained in vertebrate Rab32, we can assume Rab32 function in melanogenesis as ancestral. In zebrafish this gene has acquired new roles in the formation of other lysosome related organelles.

Zebrafish shows a varied scenario of Rab32s and Rab38s expressions with a high spatio-temporal diversification due to genomic events that occurred during the evolution of vertebrates. The three zebrafish Rab38s are expressed in distinct embryonic territories (Fig. 6), including pigmented cells, swim bladder and nervous system, unravelling a functional paralogous diversification. Distinct types of duplications have permitted the functional specialization in pigmentation of one of the paralogues [40]. The TSGD provided further raw genetic material for the evolution of teleost pigmentation patterns [33, 40]. The expression data of the three zebrafish Rab38s are an example of ancestral function distribution among duplicates (sub-functionalization).

Finally, the amphioxus Rab32/38 expression territories in the notochord and pharynx (Fig. 4b, c, d) are consistent with transient zebrafish $R a b 32 a$ expression in the notochord and Rab38b in pharyngeal arches. This findings suggest possible ancestral roles of the prechordate Rab32/38, which seem to be lost in tetrapods.

\section{Conclusions}

Our study focused on genes belonging to the Rab family known to be involved in melanosome formation in mammals: Rab32 and Rab38. Phylogenetic, intron conservation and synteny analyses of these genes in deuterostomes point towards an evolutionary scenario based on a duplication of a single invertebrate Rab32/38 gene giving rise to vertebrate ohnologs Rab32 and Rab38. Additional duplicates arose in bony fishes by teleost-specific genome duplication and expression pattern of Rab38 paralogues in zebrafish evokes sub-functionalization event. Finally, the discovery of a chromosomal linkage between the Rab32 or Rab38 gene with a Grm1 or Grm5 opens new perspectives on possible conserved bystander gene regulation across the vertebrate evolution.
However, future studies are necessary to investigate the presence of shared enhancer and to test functionally its regulative properties.

\section{Methods \\ Phylogenetic analysis}

The sequences used for the evolutionary analysis were retrieved from the NCBI (http://www.ncbi.nlm.nih.gov) and Ensembl (http://www.ensembl.org/index.html) databases (see Additional files 1 and 2). C. intestinalis Rab32/38 was the initial query sequence used for tBlastn [62] in invertebrate genomes, and reciprocal blasts were performed on each genome. The proteins were aligned by ClustalW with default parameters [63]. The phylogenetic trees were computed employing the MaximumLikelihood estimation (MLE) using MEGA6 with 1,000 replicates and the WAG $+\gamma+\mathrm{I}$ matrix [64]. The graphical representation of trees was created with Dendroscope [65]. The main Rab domains showed in Fig. 2 have been aligned manually. The synteny among deuterostome genomes was studied by manually mapping the genes on the scaffolds/chromosomes using available public resources.

\section{Cloning and riboprobe preparation}

Amphioxus Rab32/38 was cloned from a mix of embryonic stages from gastrula to 5 days-old larvae fixed in Trizol (EuroClone). Zebrafish Rab32 and Rab38 genes were cloned using the prediction available in the NCBI database: Rab32a (BC066502), Rab38a (XM_001342839.2), Rab38b (XM_003199354.1) and Rab38c (XM_685900.3). For all of them except the last one, we found expressed sequence tags (ESTs) in several developmental stages and body structures (see Additional file 10). The cDNA sequences were PCR-amplified using the following oligonucleotide pairs: BlRab32/38-F (CACAAACCTCACAC CTTCCA) and BlRab32/38-R (TGGTTCATCTGTG CTCGTTC) for amphioxus Rab32/38, BlRab32LO-F (TCGGACAGCAGAAACAACAC) and BlRab32LO-R (CTGCTCAGCTTCAGGATGTG) for amphioxus Rab32LO, DrRab32a-F (GTTGCACAGAGTTGCCA AAA) and DrRab32a-R (GTGTCTGTCAACCCCTG GAT) for zebrafish Rab32a, DrRab38a-F (TGGGG AAAACCAGCATTATC) and DrRab38a-R (TGCT GCGGTGAAATAGTGTC) for zebrafish Rab38a, DrRab38b-F (CATGACGCGGGTTTATTACA) and DrRab38b-R (TGGGTCCTTATCGGTGACTT) for zebrafish Rab38b, and DrRab38c-F (GCATCTGTTC AAAGTTCTGG) and DrRab38c-R (TGACTTGGA ACACGTCATGC) for zebrafish Rab38c. The amplified gene fragments were cloned with the TOPO-TA II Cloning Kit (Invitrogen). Correct cloning was confirmed by sequencing of both DNA strands. One $\mu \mathrm{g}$ of purified DNA was used for in vitro transcription of 
the DIG-labeled riboprobes, using SP6 and T7 RNA polymerases (Roche). The ribonucleic probes were purified using $4 \mathrm{M}$ lithium chloride $(\mathrm{LiCl})$ and stored at $-80{ }^{\circ} \mathrm{C}$ until use. The transcripts abundance in amphioxus (Branchiostoma lanceolatum) was evaluated by real time RT-PCR (see Additional file 9).

\section{Amphioxus and zebrafish embryos}

Adult amphioxus (Branchiostoma lanceolatum) were collected in the Gulf of Naples (Italy) and maintained in an open seawater circulation aquaculture under a $14 \mathrm{~h}$ light $/ 10 \mathrm{~h}$ dark cycle. Animals were reared in tanks with $10 \mathrm{~cm}$ of sand from the collection site and fed daily with a mix of the following unicellular algae: Dunaliella tertiolecta, Isochrysis galbana and Tetraselmis suecica. Spawning was induced in the laboratory in late spring by applying a thermic shock, as reported in Fuentes et al. [66]. After in vitro fertilization, embryos were cultured in $0,22 \mu \mathrm{m}$ filtered seawater at $18{ }^{\circ} \mathrm{C}$ in plastic petri dishes, and fixed at different developmental stages with $4 \%$ paraformaldehyde (PFA) in MOPS buffer overnight at $4{ }^{\circ} \mathrm{C}$, and then stored in $70 \%$ ethanol at $-20{ }^{\circ} \mathrm{C}$.

Zebrafish (Danio rerio) embryos up to $4 \mathrm{dpf}$ were obtained from natural spawning of wild-type animals and fixed overnight in $4 \%$ PFA dissolved in phosphate buffered saline (PBS), then washed in PBS and kept in methanol at $-20{ }^{\circ} \mathrm{C}$.

\section{Animal ethics}

The protocols for handling of zebrafish and experiments involving not feeding larvae were approved by the ethical committee of the Stazione Zoologica Anton Dohrn of Napoli, Italy (Animal Welfare Body).

\section{Whole-mount in situ hybridization}

Whole-mount in situ hybridization (WISH) in amphioxus was performed as described in Irimia et al. [67]. Briefly, after embryo re-hydration, digestion with Proteinase K $(5 \mu \mathrm{g} / \mathrm{ml})$ was performed to facilitate the riboprobe penetration; the reaction was stopped by adding $4 \mu \mathrm{l}$ of $10 \%$ glycine and then washed with $2 \mathrm{mg} / \mathrm{ml}$ glycine in a phosphate buffered saline solution containing Tween $200.1 \%$ (PBT). The embryos were refixed in PBT containing $4 \%$ PFA for $1 \mathrm{~h}$ at RT and then washed in $0.1 \mathrm{M}$ triethanolamine with acetic anhydride to bleach the natural pigments of the embryos. Embryos were washed with PBT several times and hybridized $\mathrm{ON}$ at $65{ }^{\circ} \mathrm{C}$ in $\mathrm{DEPC}-\mathrm{H}_{2} \mathrm{O}$ hybridization buffer (50\% deionized formamide; $100 \mu \mathrm{g} /$ ml Heparin; 5× SSC; $0.1 \%$ Tween20; 5 mM EDTA; $1 \times$ Denhardt's $1 \mathrm{mg} / \mathrm{ml} ; 50 \mathrm{mg} / \mathrm{ml}$ yeast RNA).

In zebrafish, whole-mount in situ hybridization (WISH) was performed as described by Thisse et al. [68]. Briefly, after embryo re-hydration, digestion with Proteinase $\mathrm{K}$ $(10 \mu \mathrm{g} / \mathrm{ml})$ was performed to permeabilize the embryonic tissues, and the reaction was stopped by fast washes in PBT. The embryos were refixed in $4 \%$ PFA in PBT for $1 \mathrm{~h}$ at RT and washed with PBT many times. They were hybridized $\mathrm{ON}$ at $65{ }^{\circ} \mathrm{C}$ in hybridization buffer in DEPC$\mathrm{H}_{2} \mathrm{O}$ (50 \% Formammide; $100 \mu \mathrm{g} / \mathrm{ml}$ Heparin; $1.3 X$ SSC; $0.2 \%$ Tween20; $5 \mathrm{mM}$ EDTA $\mathrm{pH} 8,0 ; 50 \mu \mathrm{g} / \mathrm{ml}$ Yeast RNA; $0.5 \%$ CHAPS).

Embryo image capturing was performed with a Zeiss Axio Imager M1.

\section{Additional files}

Additional file 1: Accession number of sequences used in the evolutionary analysis. (XLSX $19 \mathrm{~kb}$ )

Additional file 2: Database of sequences used in phylogeny of Fig. 1. (TXT $14 \mathrm{~kb}$ )

Additional file 3: Vertebrate Rab32 and Rab38 phylogeny. (PDF $178 \mathrm{~kb}$ )

Additional file 4: Database of sequences used in phylogeny of Additional file 3. (TXT $5 \mathrm{~kb}$ )

Additional file 5: Intron conservation. This survey inferred the existence of a conserved intron code in Rab32 and Rab38 subfamily retained after a vertebrate duplication. Switch I (partial) and Switch II domains are underlined. (DOCX $15 \mathrm{~kb}$ )

Additional file 6: Phylogenies of Tab, Nox, Fzd, Stxbp. (PDF 378 kb) Additional file 7: GRM phylogeny. (PDF $282 \mathrm{~kb}$ )

Additional file 8: Additional syntenic studies. A. Human chromosome 11 and mouse chromosome 7: a focus on Rab38 gene loci with, respectively, a TRIM gene family expansion and an extraordinary clustering of olfactory genes: Vomeronasal 2 receptor $(\mathrm{Vmn} 2 \mathrm{r}$ ) and Olfactory Receptor (OR) in mouse; B Microsynteny of Rab32LO between echinoderms and cephalochordates. (PPTX $72.8 \mathrm{~kb}$ )

Additional file 9: Gene expression profile during amphioxus development. Rab32/38 and Rab32LO gene expression profiles by real time RT-PCR during Branchiostoma lanceolatum development. Both genes have been normalized using the ribosomal protein L32 (RPL32) expression using the same cDNA template. (DOCX $41.4 \mathrm{~kb}$ )

Additional file 10: Zebrafish ESTs available in NCBI database. (XLSX $10.5 \mathrm{~kb})$

Competing interests

The authors declare that they have no competing interests.

Authors' contributions

UC carried out the molecular evolution analyses, performed in situ hybridization assays and drafted the manuscript. GA carried out experiments on amphioxus embryos and contributed to draft the manuscript. SD and FR designed and coordinated the study, analyzed the data and contributed to draft the manuscript. All authors read and approved the final manuscript.

\section{Acknowledgements}

The authors thank Prof. Ricard Albalat Rodriguez, Dr. Juan Pascual-Anaya and Dr. Paolo Sordino for helpful critical discussions, Alberto Macina and Davide Caramiello of the Marine Resources for Research Unit of Stazione Zoologica Anton Dohrn of Napoli for amphioxus long-term maintenance. Ugo Coppola has been supported by a SZN PhD fellowship. This work has been partially supported by a Marie Curie Career Integration Grant (FP7-PEOPLE) to Salvatore D'Aniello (PCIG09-GA-2011-293871).

Received: 11 August 2015 Accepted: 18 January 2016

Published online: 27 January 2016 


\section{References}

1. Stenmark H. Rab GTPases as coordinators of vesicle traffic. Nat Rev Mol Cell Biol. 2009;10(8):513-25.

2. Diekmann Y, Seixas E, Gouw M, Tavares-Cadete F, Seabra MC, Pereira-Leal JB. Thousands of rab GTPases for the cell biologist. PLoS Comput Biol. 2011; 7(10), e1002217.

3. Brighouse A, Dacks JB, Field MC. Rab protein evolution and the history of the eukaryotic endomembrane system. Cell Mol Life Sci. 2010;67(20):3449-65.

4. Park HH. Structural basis of membrane trafficking by rab family small $\mathrm{g}$ protein. Int J Mol Sci. 2013;14(5):8912-23.

5. Klopper TH, Kienle N, Fasshauer D, Munro S. Untangling the evolution of Rab G proteins: implications of a comprehensive genomic analysis. BMC Biol. 2012;10:71.

6. Bright LJ, Kambesis N, Nelson SB, Jeong B, Turkewitz AP. Comprehensive analysis reveals dynamic and evolutionary plasticity of Rab GTPases and membrane traffic in Tetrahymena thermophila. PLoS Genet. 2010:6(10), e1001155.

7. Carlton JM, Hirt RP, Silva JC, Delcher AL, Schatz M, Zhao Q, et al. Draft genome sequence of the sexually transmitted pathogen Trichomonas vaginalis. Science. 2007;315(5809):207-12.

8. Saito-Nakano Y, Nakahara T, Nakano K, Nozaki T, Numata O. Marked amplification and diversification of products of ras genes from rat brain, Rab GTPases, in the ciliates Tetrahymena thermophila and Paramecium tetraurelia. J Eukaryot Microbiol. 2010;57(5):389-99.

9. Pereira-Leal JB, Seabra MC. Evolution of the Rab family of small GTP-binding proteins. J Mol Biol. 2001;313(4):889-901.

10. Rutherford S, Moore I. The Arabidopsis Rab GTPase family: another enigma variation. Curr Opin Plant Biol. 2002;5(6):518-28.

11. Elias M, Brighouse A, Gabernet-Castello C, Field MC, Dacks JB. Sculpting the endomembrane system in deep time: high resolution phylogenetics of Rab GTPases. J Cell Sci. 2012;125(Pt 10):2500-8.

12. Wasmeier C, Romao M, Plowright L, Bennett DC, Raposo G, Seabra MC. Rab38 and Rab32 control post-Golgi trafficking of melanogenic enzymes. J Cell Biol. 2006;175(2):271-81.

13. Nilsson Skold H, Aspengren S, Wallin M. Rapid color change in fish and amphibians - function, regulation, and emerging applications. Pigment Cell Melanoma Res. 2013;26(1):29-38.

14. Esposito R, D'Aniello S, Squarzoni P, Pezzotti MR, Ristoratore F, Spagnuolo A New insights into the evolution of metazoan tyrosinase gene family. PLoS One. 2012;7(4), e35731.

15. Bultema JJ, Ambrosio AL, Burek CL, Di Pietro SM. BLOC-2, AP-3, and AP-1 proteins function in concert with Rab38 and Rab32 proteins to mediate protein trafficking to lysosome-related organelles. J Biol Chem. 2012;287(23):19550-63.

16. Loftus SK, Larson DM, Baxter LL, Antonellis A, Chen Y, Wu X, et al. Mutation of melanosome protein RAB38 in chocolate mice. Proc Natl Acad Sci U S A. 2002; 99(7):4471-6.

17. Abi-Rached L, Gilles A, Shiina T, Pontarotti $P$, Inoko $H$. Evidence of en bloc duplication in vertebrate genomes. Nat Genet. 2002;31(1):100-5.

18. Dehal $P$, Boore JL. Two rounds of whole genome duplication in the ancestral vertebrate. PLoS Biol. 2005;3(10), e314.

19. Ohno S. Patterns in genome evolution. Curr Opin Genet Dev. 1993; 3(6):911-4.

20. Oiso N, Riddle SR, Serikawa T, Kuramoto T, Spritz RA. The rat Ruby (R) locus is Rab38: identical mutations in Fawn-hooded and Tester-Moriyama rats derived from an ancestral Long Evans rat sub-strain. Mamm Genome. 2004;15(4):307-14

21. Wei ML. Hermansky-Pudlak syndrome: a disease of protein trafficking and organelle function. Pigment Cell Res. 2006;19(1):19-42.

22. Hermansky F, Pudlak P. Albinism associated with hemorrhagic diathesis and unusual pigmented reticular cells in the bone marrow: report of two cases with histochemical studies. Blood. 1959;14(2):162-9.

23. Park M, Serpinskaya AS, Papalopulu N, Gelfand VI. Rab32 regulates melanosome transport in Xenopus melanophores by protein kinase a recruitment. Curr Biol. 2007:17(23):2030-4.

24. Delsuc F, Brinkmann H, Chourrout D, Philippe $H$. Tunicates and not cephalochordates are the closest living relatives of vertebrates. Nature. 2006:439(7079):965-8.

25. Racioppi C, Kamal AK, Razy-Krajka F, Gambardella G, Zanetti L, di Bernardo $D$, et al. Fibroblast growth factor signalling controls nervous system patterning and pigment cell formation in Ciona intestinalis. Nat Commun. 2014;5:4830
26. Tsuda M, Sakurai D, Goda M. Direct evidence for the role of pigment cells in the brain of ascidian larvae by laser ablation. J Exp Biol. 2003; 206(Pt 8):1409-17.

27. Wang C, Liu Z, Huang X. Rab32 is important for autophagy and lipid storage in Drosophila. PLoS One. 2012;7(2), e32086.

28. Ma J, Plesken H, Treisman JE, Edelman-Novemsky I, Ren M. Lightoid and Claret: a rab GTPase and its putative guanine nucleotide exchange factor in biogenesis of Drosophila eye pigment granules. Proc Natl Acad Sci U S A. 2004;101(32):11652-7.

29. Putnam NH, Butts T, Ferrier DE, Furlong RF, Hellsten U, Kawashima T, et al. The amphioxus genome and the evolution of the chordate karyotype. Nature. 2008:453(7198):1064-71.

30. Lacalli TC. Sensory systems in amphioxus: a window on the ancestral chordate condition. Brain Behav Evol. 2004;64(3):148-62.

31. Vopalensky P, Pergner J, Liegertova M, Benito-Gutierrez E, Arendt D, Kozmik Z. Molecular analysis of the amphioxus frontal eye unravels the evolutionary origin of the retina and pigment cells of the vertebrate eye. Proc Natl Acad Sci U S A. 2012;109(38):15383-8.

32. Yu JK, Meulemans D, McKeown SJ, Bronner-Fraser M. Insights from the amphioxus genome on the origin of vertebrate neural crest. Genome Res. 2008;18(7):1127-32.

33. Braasch I, Schartl M, Volff JN. Evolution of pigment synthesis pathways by gene and genome duplication in fish. BMC Evol Biol. 2007;7:74.

34. Sugimoto M. Morphological color changes in fish: regulation of pigment cell density and morphology. Microsc Res Tech. 2002;58(6):496-503.

35. Jaillon O, Aury JM, Brunet F, Petit JL, Stange-Thomann N, Mauceli E, et al. Genome duplication in the teleost fish Tetraodon nigroviridis reveals the early vertebrate proto-karyotype. Nature. 2004;431(7011):946-57.

36. Taylor JS, Braasch I, Frickey T, Meyer A, Van de Peer Y. Genome duplication, a trait shared by 22000 species of ray-finned fish. Genome Res. 2003;13(3):382-90.

37. Taylor JS, Van de Peer Y, Braasch I, Meyer A. Comparative genomics provides evidence for an ancient genome duplication event in fish. Philos Trans R Soc Lond B Biol Sci. 2001;356(1414):1661-79.

38. Hoegg S, Brinkmann H, Taylor JS, Meyer A. Phylogenetic timing of the fish-specific genome duplication correlates with the diversification of teleost fish. J Mol Evol. 2004:59(2):190-203.

39. Kuraku S, Meyer A. The evolution and maintenance of Hox gene clusters in vertebrates and the teleost-specific genome duplication. Int J Dev Biol. 2009;53(5-6):765-73.

40. Braasch I, Brunet F, Volff JN, Schartl M. Pigmentation pathway evolution after whole-genome duplication in fish. Genome Biol Evol. 2009;1:479-93.

41. Venkatesh B, Lee AP, Ravi V, Maurya AK, Lian MM, Swann JB, et al. Elephant shark genome provides unique insights into gnathostome evolution. Nature. 2014;505(7482):174-9.

42. Amores A, Catchen J, Ferrara A, Fontenot Q, Postlethwait JH. Genome evolution and meiotic maps by massively parallel DNA sequencing: spotted gar, an outgroup for the teleost genome duplication. Genetics. 2011;188(4): 799-808.

43. Namkoong J, Shin SS, Lee HJ, Marin YE, Wall BA, Goydos JS, et al. Metabotropic glutamate receptor 1 and glutamate signaling in human melanoma. Cancer Res. 2007;67(5):2298-305.

44. Shin SS, Namkoong J, Wall BA, Gleason R, Lee HJ, Chen S. Oncogenic activities of metabotropic glutamate receptor 1 (Grm1) in melanocyte transformation. Pigment Cell Melanoma Res. 2008;21(3):368-78.

45. Fatemi SH, Folsom TD, Rooney RJ, Thuras PD. mRNA and protein expression for novel GABAA receptors theta and rho2 are altered in schizophrenia and mood disorders; relevance to FMRP-mGluR5 signaling pathway. Transl Psychiatry. 2013;3, e271

46. Skafidas E, Testa R, Zantomio D, Chana G, Everall IP, Pantelis C. Predicting the diagnosis of autism spectrum disorder using gene pathway analysis. Mol Psychiatry. 2014;19(4):504-10.

47. Leinders-Zufall $T$, Ishii $T$, Chamero $P$, Hendrix $P$, Oboti L, Schmid A, et al. A family of nonclassical class I MHC genes contributes to ultrasensitive chemodetection by mouse vomeronasal sensory neurons. J Neurosci. 2014:34(15):5121-33.

48. Godfrey PA, Malnic B, Buck LB. The mouse olfactory receptor gene family. Proc Natl Acad Sci U S A. 2004;101(7):2156-61.

49. Carthagena L, Bergamaschi A, Luna JM, David A, Uchil PD, Margottin-Goguet F, et al. Human TRIM gene expression in response to interferons. PLoS One. 2009; 4(3), e4894.

50. Muhlenbein N, Hofmann S, Rothbauer U, Bauer MF. Organization and function of the small Tim complexes acting along the import pathway of 
metabolite carriers into mammalian mitochondria. J Biol Chem. 2004; 279(14):13540-6.

51. Thisse B, Pflumio S, Fürthauer M, Loppin B, Heyer V, Degrave A, et al. Expression of the zebrafish genome during embryogenesis (NIH R01 RR15402). ZFIN Direct Data Submission (http://zfinorg). 2001.

52. Virta VC, Cooper MS. Structural components and morphogenetic mechanics of the zebrafish yolk extension, a developmental module. J Exp Zool B Mol Dev Evol. 2011;316(1):76-92.

53. D'Aniello S, Irimia M, Maeso I, Pascual-Anaya J, Jimenez-Delgado S, Bertrand $\mathrm{S}$, et al. Gene expansion and retention leads to a diverse tyrosine kinase superfamily in amphioxus. Mol Biol Evol. 2008;25(9):1841-54.

54. Ravi V, Lam K, Tay BH, Tay A, Brenner S, Venkatesh B. Elephant shark (Callorhinchus milii) provides insights into the evolution of Hox gene clusters in gnathostomes. Proc Natl Acad Sci U S A. 2009;106(38):16327-32.

55. Bultema JJ, Di Pietro SM. Cell type-specific Rab32 and Rab38 cooperate with the ubiquitous lysosome biogenesis machinery to synthesize specialized lysosome-related organelles. Small GTPases. 2013;4(1):16-21.

56. Irimia M, Tena JJ, Alexis MS, Fernandez-Minan A, Maeso I, Bogdanovic O, et al. Extensive conservation of ancient microsynteny across metazoans due to cis-regulatory constraints. Genome Res. 2012;22(12):2356-67.

57. Cohen-Solal KA, Sood R, Marin Y, Crespo-Carbone SM, Sinsimer D, Martino $\mathrm{JJ}$, et al. Identification and characterization of mouse Rab32 by mRNA and protein expression analysis. Biochim Biophys Acta. 2003;1651(1-2):68-75.

58. Osanai K, Takahashi K, Nakamura K, Takahashi M, Ishigaki M, Sakuma T, et al. Expression and characterization of Rab38, a new member of the Rab small G protein family. Biol Chem. 2005;386(2):143-53.

59. Zhang L, Yu K, Robert KW, DeBolt KM, Hong N, Tao JQ, et al. Rab38 targets to lamellar bodies and normalizes their sizes in lung alveolar type ॥ epithelial cells. Am J Physiol Lung Cell Mol Physiol. 2011;301(4):L461-77.

60. Ellis K, Bagwell J, Bagnat M. Notochord vacuoles are lysosome-related organelles that function in axis and spine morphogenesis. J Cell Biol. 2013;200(5):667-79.

61. Torday JS, Rehan VK. Deconvoluting lung evolution using functional/ comparative genomics. Am J Respir Cell Mol Biol. 2004;31(1):8-12.

62. Gertz EM, Yu YK, Agarwala R, Schaffer AA, Altschul SF. Composition-based statistics and translated nucleotide searches: improving the TBLASTN module of BLAST. BMC Biol. 2006:4:41.

63. Thompson JD, Higgins DG, Gibson TJ. CLUSTAL W: improving the sensitivity of progressive multiple sequence alignment through sequence weighting, position-specific gap penalties and weight matrix choice. Nucleic Acids Res. 1994;22(22):4673-80.

64. Tamura K, Stecher G, Peterson D, Filipski A, Kumar S. MEGA6: Molecular Evolutionary Genetics Analysis version 6.0. Mol Biol Evol. 2013;30(12):2725-9.

65. Huson DH, Scornavacca C. Dendroscope 3: an interactive tool for rooted phylogenetic trees and networks. Syst Biol. 2012;61 (6):1061-7.

66. Fuentes M, Benito E, Bertrand S, Paris M, Mignardot A, Godoy L, et al. Insights into spawning behavior and development of the European amphioxus (Branchiostoma lanceolatum). J Exp Zool B Mol Dev Evol. 2007;308(4):484-93.

67. Irimia M, Pineiro C, Maeso I, Gomez-Skarmeta JL, Casares F, Garcia-Fernandez J. Conserved developmental expression of Fezf in chordates and Drosophila and the origin of the Zona Limitans Intrathalamica (ZLI) brain organizer. Evodevo. 2010;1(1):7.

68. Thisse C, Thisse B. High-resolution in situ hybridization to whole-mount zebrafish embryos. Nat Protoc. 2008;3(1):59-69.

\section{Submit your next manuscript to BioMed Central and we will help you at every step:}

- We accept pre-submission inquiries

- Our selector tool helps you to find the most relevant journal

- We provide round the clock customer support

- Convenient online submission

- Thorough peer review

- Inclusion in PubMed and all major indexing services

- Maximum visibility for your research

Submit your manuscript at www.biomedcentral.com/submit
C Biomed Central 